\title{
\# DRAFT\#
}

\section{Stalling for Time}

Gabriel Furmuzachi

\section{Abstract}

Carel Fabritius left behind few but important works of art. We are concerned here with the View in Delft, and attempt to make two points about it. The first is that this small painting manages to break away from the classical perception of perspective, an endeavor informed mostly by new findings in the field of optics of the time. The second point, theoretically related to the first, stresses compositional elements that would bring View in Delft closer to a meditation on the fleetingness of life, making it a "town-scape" vanitas. 
The View in Delft, by Carel Fabritius (1622-1654) is a small painting (15.5 x 31.7 $\mathrm{cm})$ showing a street corner, at the back of the Nieuwe Kerk, in Delft in 1652. On the left side of the painting there is a man (perhaps a musical instruments seller) sitting in a stall at a table (on which we can see a lute and a viola da gamba) and seeming to be somehow lost in thoughts. As we look further to the right, our gaze is led inside the picture, then across the canal, acknowledging the tiny silhouette of the Delft town-hall, then come back, following the convex curvature of the Nieuwe Kerk (central to the painting) and then, again, down the road and along a second canal, our gaze travels all the way to the heart of Delft in order to finally come back again in the proximity of our instruments seller. The painting is on display at the National Gallery in London and, although it is presented flat (canvas mounted on wood) it is very likely that it was part of a perspective box.

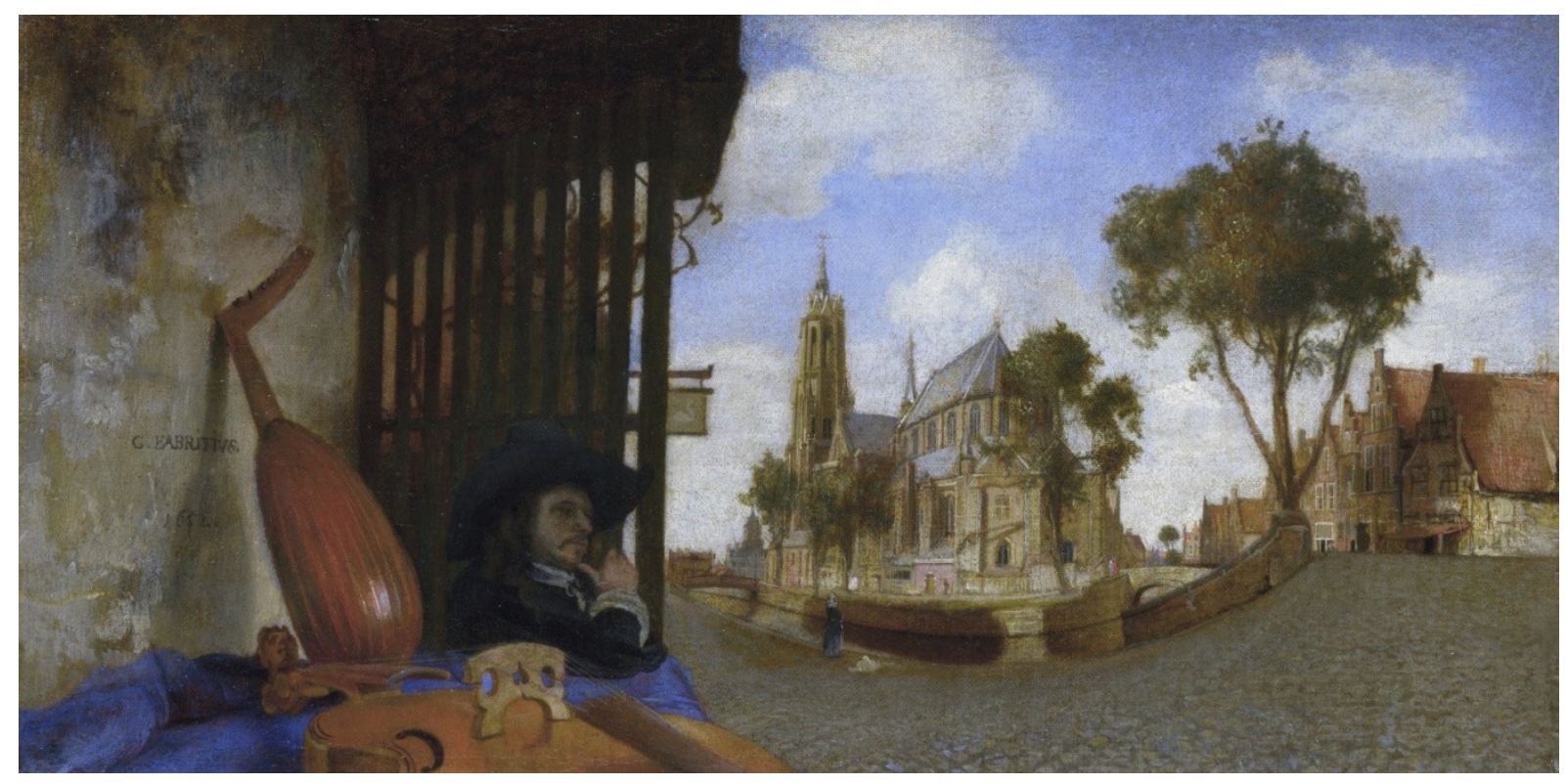

Carel Fabritius - View in Delft (1652) - 15.5 x 31.7 cm (Wikipedia)

Walter Liedtke in The Burlington Magazine (1976) brings convincing arguments supporting the fact that Fabritius not only made perspective boxes but also that he was some sort of authority in this respect. The View in Delft, Liedtke considers, was meant to be mounted at the back of a V-shaped box, in a hemicycle at $80^{\circ}$ viewing angle. Presenting it this way would give one a much better sense of depth: the tree on the right would become almost detached from the picture (with some virtual space between itself and the houses behind it), the light and shadow play would become plausible, the church would lose its plumpness and receive taller proportions and the road on the right would be, as Liedtke puts it, "less reminiscent of Champs Élysées than of this little straatje in the actual town". Moreover, the man on the left seems now "slimmer but rounder", he "occupies space and gains his proper scale" closer to the viewer than to the church. The 
rest of the viola da gamba would be completed with a drawing on the floor of the perspective box, which would thus put it right "beneath the viewer's nose", below and in contrast to the church. Fabritius plays with our gaze in this small work. This does not mean, however, that he managed to pull a sophisticated trompeI'oeil on us. Not because he were not capable of such a thing, but because he was less interested in "making the kind of illusionistic curio common in contemporary kunstkabinets than in testing the limits of mimesis in painting (an aim evidently consistent with his approach in other mature works)." (Liedtke, 1976) Liedtke also suggests that Fabritius might have come in contact, while being an apprentice in Rembrandt's studio, with ideas on perspective present in a manuscript copy of the first edition of Leonardo's Trattato della Pittura (published in Paris for the first time in 1651). We will never be able to know if that was the case, but illustrations of Leonardo's thoughts on painting seem to inform Fabritius' work. That the main aim of painting is to make a "plane surface display a body in relief, detached from that plane", or that darker objects appear detached when put against a bright background are examples to be found in Fabritius' work. "The View in Delft", considers Liedtke, "is one of the greatest and historically most significant monuments of seventeenth-century Dutch painting not because it broke with the tradition in any way, but precisely because it represents a conscious effort to extend the established representational conventions in accord with a deepening interest in the physical environment." (Liedtke, 1976) Fabritius' painting seems to be more scientifically informed than other, similar works of his time in that, as we will see, it makes use of ideas at the confluence between philosophy, science and art. Fabritius was interested not only in painting the world but also in learning how we manage to see it at all. View in Delft is not only about a small square in a Dutch city. It is also about how our eyes work when we take in the world around us. But it is also not a celebration of the way we gain knowledge, rather a disenchantment. The closer to a truthful representation it gets, View in Delft implies the extent to which we could be deceived by our own eyes, leaving us wondering, as a prominent philosopher of the time does, about the certainty of knowledge.

We know very little about Fabritius. We know (Valentiner, 1932) that he was an apprentice in Rembrandt's studio, that he married young and that by the summer of 1643 he lost both his wife and the twins she gave birth to. We also know that he remarried in 1650 and lived together with his second wife in Delft. We know that he was almost never able to run his financial life, as he seemed to have perpetually been in debt, even if he was recognized as a master artist during his time and had apprentices (one of them could have even been Vermeer himself). We know he died young (at 32 years of age) - two years after this painting was finished - in the great explosion of a gunpowder store in Delft, which also destroyed his atelier. Over a dozen paintings are known to be by his hand. It is also very likely that he painted several anamorphic murals but, sadly, none of them survived. Most of Liedtke's considerations are about the painting as an object - how it should be looked at, how the perspective works, if Fabritius used a lens (a reversed telescope, for example, as other painters of the time did; and no, apparently he did not), etc. We are not going to challenge these findings here. 
What we would like to do now is to look at the painting as a painting, as a representation: to be its spectator.

III

How should we then look at the View in Delft? This is such a small painting but it manages to pack quite a lot in terms of artistic accomplishment, geometrical perspective, symbols and emotion. If we have Fabritius' work mounted on the hemicycle and look at it through the peephole, we see it in a perspective that is almost Kafkaesque: a small bug sitting on the viola da gamba, watching the world unfold. This kind of perspective is not something we see very often in a painting. The view we are offered is not as simple nor as straightforward as we might first think. Our gaze is forced to jump from foreground to background as we watch, to focus on different subjects and at the same time keep all of them connected. Linear perspective, the only method used by painters for hundreds of years, does not inform the View in Delft. However, this was not something completely new: already in 1604 Karel van Mander offers a pictorial alternative to Alberti's method of representation, departing from the latter's ideas that the ultimate aim of the artist was to imitate nature. A painter, van Mander thinks, could make use of close views and combine them tactically with distant vistas thus realizing a "multifocal panoramic landscape, punctuated by multiple perspectives that mobilize the eye." (Brusati, 2012) Vision becomes a guided process by carefully modifying and intensifying what the eye can see. Later, Samuel Dirksz van Hoogstraten in his Introduction to the Academy of Painting (1678) writes that perspective does not render things as they are in nature but only those aspects that can be re-created by the eye in an image-making process. This process is not unlike drawing itself, where "colored forms" make their way into the eye. A good painter is one who understands that seeking to represent nature in itself is not as important as representing how the world appears to the eye. Because the same way the eye is tricked in the process of seeing should be used in making a perspective painting. The box containing the View in Delft is not a play on the eye, it is not a trick, it is not a trompe l'oeil. By containing what the spectator is allowed to see, Fabritius attempts to concentrate and focus our gaze and, at the same time to encapsulate the "madness of seeing", as Merleau-Ponty has called it. He creates a virtual space and compels the viewer to take part in it, even if only through the tiny peep hole. Merleau-Ponty pointed out in The Visible and the Invisible that when we see something we "possess" that thing, we bring the object at hand. "He who sees cannot possess the visible unless he is of it." (Merleau-Ponty 1968, 134) What Fabritius does with View in Delft is to have a go at bringing the landscape at hand, at "manipulating" it, taking it in, transferring it from something pertaining to the outside world into something happening inside, internalizing it, understanding it.

In What is Philosophy, Deleuze and Guattari (181-2) write that, throughout its history, painting actually only struggled for one thing, namely for painting forces, "forces of gravity, heaviness, rotation, the vortex, explosion, expansion, germination, and time". Now if we look again at Fabritus' painting we could notice the heaviness of the church, the revolving of feeling from the weariness of the 
instruments seller to the lightness of the woman in blue, from the explosion of the tree's branches in foreground, to the play between the finite time of the music and the sign of eternity pointed out by the church, and filtered lightly by the silky clouds. And Fabritius takes it a step further: since the forces at work here tend to pull the gaze in multiple directions he proceeds, in an attempt to bring them back in a balance, to contain and level their dynamic. He seems to want to apply force to the canvas, as well. He stretches it on a hemicycle and boxes it, making it a world in itself.

IV

But let us go back to Hoogstraten's idea, namely that perspective does not render things as they are in nature but only those aspects that can be re-created by the eye in an image-making process. Translating it in Aristotelian terms we could talk about a sort of mimesis at work here. Usually, mimesis is taken to mean "imitation" but it is actually closer to "actualization", a process where "objects, events, or actions which, because they are divine, past or canonical, belong to a more valuable domain of reality than our quotidian lives but are therefore in some way remote from us, enjoin upon us the obligation to restore their actuality." (Most 1998) Mimesis is, at least, an ambivalent term and it can both point out, depending on the circumstances, either the inferiority of actualization (as opposed to its superiror model) or, the other way around, the superiority "it acquires by its temporary participation in the model's prestige". (Most 1998). Perhaps Fabritius sensed this ambivalence and View in Delft is his answer to the question of mimesis. As we will see, it would aline very well with his understanding of vision, of what it meant for him to see the world. It was not his intention to reproduce reality in its minute details. Even if Fabritius went quite a way in "testing the limits of mimesis", he did not intend to bring up an example of..., let's call it photorealistic work (if the term were available in his time).

Photorealism takes part in a different world altogether. Photorealism, as Frederic Jameson put it, "looked like a return to representation and figuration after the long hegemony of the aesthetics of abstraction until it became clear that their objects were not to be found in the "real world" either but were themselves photographs of that real world, this last now transformed into images, of which the "realism" of the photorealist painting is now the simulacrum." (65) A photorealist painting is a painting of a photograph, which in turn is a copy of reality. Thus it appears that the simulacrum is a copy which has been removed twice from reality. After all, following Baudrillard who pointed out in his critique of postmodern society that the distinction between what is real or natural and what is artificial has been gradually lost, we could understand how the artifice managed to take over the real. Baudrillard distinguished three orders of simulacra. The first order corresponds historically to the pre-modern world where images were seen as merely illusions, faint copies of the reality. The second order is connected to the multitude, to the mass production of copies which was a typical phenomenon in the nineteenth century. The third order, of the postmodern world, brings in a kind of sovereignty of the simulacra, which go beyond copying reality, preceding and even determining it. This is where the inability to distinguish between reality and its representation comes in. If copying reality is 
what Fabritius struggles to achieve with View in Delft, we should place it into the first order of simulacra. However, one does not look at the world through a peephole, one cannot contain a copy of reality inside a box. For obvious reasons, the painting does not belong to the second order of simulacra either. What about the third? Does it precede the world, does the world take upon itself to follow Fabritius' rendering? Obviously not. What kind of representation is it then, we might ask? In an essay aptly titled Realer than Real, Brian Massumi points out, following Deleuze's thoughts on the idea of simulacrum (Plato and the Simulacrum), that we deal here with a difference in nature and not with a degree of replication: this difference "undermines" the distinction between copy and model. "The production and function of a photograph" writes Massumi, "has no relation to that of the object photographed; and the photorealist painting in turn envelops an essential difference. It is that masked difference, not the manifest resemblance, that produces the effect of uncanniness so often associated with the simulacrum. A copy is made in order to stand in for its model. A simulacrum has a different agenda, it enters different circuits." (Massumi, 1987). We could say now that View in Delft does not copy reality, it does not make a reproduction of the little square overlooking the church. It goes beyond it. It opens for us a different world altogether, a world which slowly began to be investigated in Fabritius' time, a world at the confluence of art, optics and philosophy. In his article, Massumi brings up a scene from Blade Runner, where the leading "replicant" (a bio-robotic being) tells the man who built his (mechanical) eyes: "if you could see what I have seen with your eyes". View in Delft has, of course, nothing to do with the world of android robots from Blade Runner but it has very much to do with the idea of the seeing eye. Because Fabritius' painting is the eye itself, and through it he tries to give us an insight into what the eye sees from within. The moment one looks through the peep-hole, one looks through the new eye, the one discovered by Descartes. With Descartes and his work on optics we (as well as the world of Rembrandt and Frans Hals and Fabritius and Vermeer) find out that the eye is not a window towards the world but, indeed, merely a screen.

In Dioptrics, Descartes considers that what affects the soul is not a picture representing the object we are looking at but an image of that object, an image that is not similar to the object itself but which would remind us rather of an etching - a bit imperfect, perhaps lacking in details, color, etc. Otherwise, if the object would resemble its image in all respects, we would not be able to distinguish between them anymore. The image of the object appears inside the eye even without the observer (for his experiment Descartes says one could use the "eye of a newly deceased man or of an ox or some other large animal" to make a projection of an object on the retina), even if there is nobody there to see it. Sight is no longer the substance of the eye, as it used to be for a philosopher like Aristotle. Thus, the observer is not required for the world to be seen. Already with Kepler, in 1602, the human observer starts to fade out. The eye itself becomes a sort of camera obscura, and the "pupil takes the place of the window". The image we see on a piece of paper placed inside the camera obscura is the same as the image being formed on the retina. It is imperfect and the imperfection is caused by the "accidental shape of the aperture". This means that we can trust the instrument (a device like camera obscura or the telescope) as much as we can trust the eye: science becomes henceforth the "guarantor" of 
vision's "limited reliability". (Gal and Chen-Morris, 2010) However, we should not forget that the reverse is, unfortunately, also true and that whatever flaws the instrument might have, could also be encountered as flaws in the eye itself. Visual errors, unlike the Aristotelian view where human imagination would intervene in seeing and consequently alter it, are now thought to happen due to the structure of vision itself. The images the eye would be able to offer are rather fuzzy as they are caused by light effects; they do not and cannot show a precise likeness to the objects focused on. Descartes points out that owing to the flawed way we see, the eye is not to be trusted. In order to develop his system he needed something like the eye but stable and trustworthy. His trouvaille was "the eye of the mind" which would see more clearly as long as the eye of the flesh would steer away from the abundance of sense perception. Thus, "he invented the eye of the mind, modeled on but completely independent from the eye of the flesh, and in this reversed the epistemological role of vision. From being the guarantor of our knowledge and a paradigm of direct acquaintance, vision became a metaphor for mediation. It was a paradoxical insight: by accepting that knowing is seeing and understanding how we see, Descartes was convinced that we may not know at all." (Gal and Chen-Morris, 2010)

That we may not know at all... Would it be possible that Fabritius somehow managed to grasp how serious the findings of the optics of his time and of the views philosophers held on light and color were for his own work and for painting in general? Would it be possible that he wanted to experiment for himself and in his own way and thus played with anamorphic murals and perspective boxes while at the same time continued to paint as his master did or, better still, as his master would? How much do we know when we look at View in Delft? How much do we understand of the world when we see it from the Kafkaesque perspective Fabritius is offering us? Do we see more if his manipulation is more dexterous? It seems, the longer one looks at this painting the less certain one becomes as to what one actually sees.

In her book on the Rhethoric of Perspective (2006), Hanneke Grootenboer, writing about anamorphosis, brings forth some pictures of Dutch photographer Jan Dibbets who, in a series called Perspective Correction (1969), plays with our gaze quite like Fabritius did a few centuries earlier, although Dibbets presents us with an "anamorphosis in reverse", as Grootenboer calls it (where we do not need to wade our way through lines and colors in order to find the hidden picture, as one normally does with anamorphosis representations). Watching Perspective Correction we wonder first where exactly is the correction. Something happened to the image, we can feel it, but we do not know what it could be or where. For example, in \#3 we see the inside corner of a studio, and we can follow the wall on the left hand side as it continues toward the vanishing point, merging with the other wall in the background at a right angle, clearly forming a perspectival structure. Now, on the wall on the left we can see a square which - and here comes the "Aha!" moment - seems to have been drawn on the photograph rather than on the wall itself, as it skips the perspective distortion altogether. It is still a perfectly good square and not an elongated geometrical structure, as if it escaped the laws of perspective. It is as if the square floats inside the picture, not affected by the forces at work in this representation, as if it would establish its own space, as if there were no model for it in the real world. Here we can see once again how vision becomes a metaphor for mediation between the eye of the mind and the eye of the flesh. Dibbets manages to show that what we see and 
what we expect to see are two different things, that the usual way we look at the world in perspective can be simply distorted, or as he put it, corrected. Fabritius paints a picture, which he distorts in order to bring it closer to a more faithful representation of the world. Dibbets takes a photograph (in other words, he makes a copy) of a world, part of which does not seem to fit in with the rest, like a ghost from another dimension. As if the truthful eye of the camera is corrected by a second, invisible eye.

Dibbets corrects perspective by altering the real object, by changing the environment itself, whereas Fabritius changes the medium, the canvas and stretches it in an unusual though more faithful manner to the act of seeing.

Except, perhaps, for the light summer breeze slowly pushing the light clouds, there is no impression of sound, not even of noise or of something going on in the background. We could almost think of View in Delft as a still life with musical instruments. The quietness of the scene points out an intention to avoid a textual interpretation. Although describing it makes possible a linguistic approximation of this painting's meaning, the trouble is, as soon as we are done describing and we rejoin its parts into a whole, we clash once more against its muteness. We still do not know what this painting is trying to say to us. The question is then, what if it does not want to say anything but instead only attempts to make us think, to make us connect with it visually and not verbally? Encapsulating it in a box, Fabritius made it available to only one viewer at a time. This means that View in Delft does not prompt us to interpretation but to seeing and thinking. In order to understand it, we need not reason about it verbally but look at it (and only at it) as close as the peephole allows us. How does a painting think? Drawing on an analysis of perspective, Grootenboer writes that "Painting is a kind of thinking and perspective serves as a rhetoric of the image. ... The rhetoric of perspective convinces us of that which painting shows, while it provides a method for that which painting thinks" (Grootenboer, 10). Grootenboer's idea to look at perspective as a method for thinking comes from Walter Benjamin who claimed in his thoughts about allegory that a philosophical writing is nothing but an allegory for truth. Benjamin does not regard philosophy as a privileged way of bringing up concepts or as a "trans-linguistic generation of principles" (Cowan, Bainard) but as allegorical literature. A philosophical treatise does not come up with proofs, according to Benjamin, but it only represents its object anew. The way a philosophical writing acts as an allegory for truth, so does in painting, perspective act as a rhetoric of the image. It does not produce reality, it only re-arranges our apprehension of it. Perspective has thus an epistemological relevance since it is a kind of thinking about the way we relate to representation itself. As Hubert Damisch put it in The Origin of Perspective:

"In the art of painting the impact of perspective is not limited to the register of the imaginary; it not only facilitates the construction of images, it assumes a role, a function that we may properly designate as symbolic. Perspective, I repeat, is not a code, but it has this in common with language, that in and by itself it institutes and constitutes itself under the auspices of a point, a factor analogous to the 'subject' or 'person' in language, always posited in relation to a 'here' or 
'there', accruing all the possibilities for movement from one position to another that this entails." (Damisch, 53)

In other words, a painting speaks to us quite in the same way a book speaks to us. If a book is a story told by a narrator, a painting is a story shown from a certain perspective. Through perspective a painting delineates its world, shows what should be shown and hides what should be guessed. Going back to Deleuze and Guattari, we could say now about perspective painting that it coordinates forces in relation to a subject and that it arranges them according to a logic of the space (where logic should be taken as a mode of reasoning). If we are right in our assumption that Fabritius tries to give us an account of seeing as it appears to the eye itself (we are talking here about the eye of the flesh) then, the perspective at work in View in Delft gives us the chance to also have a glimpse at the thinking eye, at the eye of the mind. We deal here with a painting which thinks it is an eye and which invites us to think about seeing as well, to see how we see.

We could say now that View in Delft is not a landscape in the traditional sense of the word. Or not only. It shrinks its view field to just a street crossing but it also enlarges it by going deeper inside. It also paints a portrait (of the seller in his stall) albeit only partially. Fabritius managed to be one of the first painters to zoom in to a landscape and give us a townscape and, at the same time, zoom in to a person inside the townscape and give us a portrait. The townscape seems to quietly record life as it happened on a street in a generic Dutch city. A snapshot, much in the way tourists today take photos of places they visit. Looking at it this way, View in Delft could be just another piece in the portrait of Holland of the time, as is much of Dutch painting of the Golden Age, an observation which is in tune to Eugene Fromentin's Les Maitres d'autrefois, where he suggested that Dutch painting was essentially a portrait. A portrait of Holland as "des hommes et des lieux, des moeurs bourgeoises, des places, des rues, des campagnes, de la mer et du ciel, tel devait être, réduit à ses éléments primitifs, le programme suivi par l'école hollandaise, et tel il fut depuis le premier jour jusqu'à son déclin." Fromentin celebrates a democratization of painting, where scenes were not laden with the heavy symbolism of classical antiquity but where the depicted subjects were easily recognizable and their deeds were easily placeable.

\#

But then again, we should not forget that vision is madness and Fabritius seems to have been aware of it. The reality he makes visible compels us to assume his perspective and when we do, we find ourselves sharing this Kafkaesque point of view avant la date. We are, as spectators, a tiny speck of life as significant as the little peephole allows us to be, but from that vantage point we permeate inside the world with its people and houses and trees and fluffy clouds. In a different take on Dutch Golden Age, Paul Claudel considers that Dutch painting was 
actually focused on expressing feelings and not depicting events. Dutch landscape paintings express a sense of space, of our place in the cosmos; genre interiors depict aspects of time. "Claudel sees paintings by Vermeer, De Hooch, Metsu, Dou and Terborch as essentially abstract in theme even though they appear to show contemporary reality. A woman reading a letter evokes absence; a woman looking in a mirror, reflection; a figure in a window, the dialogue between interiority and the external world." (Kelly, 2003) Claudel points out the invitation to meditation present in Dutch paintings, in reaching within ourselves and pondering on our own being here. The two worlds of the painting, as Fabritius shows, rather than being separated, are being brought together by the spectator.

Fragmenting perspective, Fabritius manages to show something about both our place in the cosmos and about a fluid aspect of time. The playfulness of music (hinted at by the instruments) is stopped short by the pensive and (perhaps) gloomy attire of the man in the stall. Music (as also life) are transitory things. They both take place in time and they both expire as soon as nobody plays the instruments or as soon as our body gives up. The church, a sign of eternity and redemption, in the way it is depicted by Fabritius does not, however, bring us reassurance nor helps us transcend the feeling of insignificance which we have when we think about our place in the universe. It does not offer us a glorious moment of reconnection with eternity as it would were it shown from the front, in all its might. Would this be a way to point out eternity? By emphasizing death? The more one looks at this painting, the more one could see how it develops into a sort of (well) hidden vanitas painting. By the time Fabritius painted the View, the royal crypt of the Nieuwe Kerk (which actually is placed at the back of the church) was quite packed: William the Silent, Maurice of Nassau, Frederick Henry, William II, etc. Moreover, the tragic story of the William II who died of smallpox only three years after his father (Frederick Henry) must have been still fresh in the mind of the Delft people (Fabritius finished the View one year later, in 1652). We should not forget that, concurently, the Dutch of his time were extremely rich. After shaking Spanish control and the Union of Utrecht in 1579 led to the emergence of the Dutch Republic, the global trade and banking flourished and the Dutch upper class reigned over immense wealth. But however rich and powerful one could be, one would still not be able to achieve immortality. Death is always lurking around every bend. As a matter of fact, while the painting came into being, the Dutch were engaged in fighting the first of what will be known as the Anglo-Dutch wars a conflict spawning over more than a century.

Transitory. This could be the word that best describes the scene Fabritius presents us with; a townscape vanitas, a meditation on the hollowness of earthly life which, however rich and wonderful can be, it is still ephemeral. Much like the hollow instruments on the table. The seller himself seems to have fallen into a melancholy state, pondering on the fleetingness of life, stalling for time. Vanitas means literally "emptiness". As we noted above, View in Delft is a silent picture, without a message, hollow. Its rhetoric lies in perspective, in harnessing the forces of "gravity, heaviness, time...". As with perspective, putting the painting in a box, trying to contain the madness of seeing, a vanitas tries to combine 
"complexities of the ontological difference between being and nothingness with the impenetrabile passing of time and the inevitability of death." (Grootenboer, 137-138) Nonetheless, the vanitas of the View in Delft is considerably more refined when compared, for example, to David Bailly's painting Vanitas: Still life with portrait of a Young Painter from 1651. Bailly's work is packed with symbols ranging from a skull to a smoking candle, an hour glass and soap bubbles to portraits and sculptures, dying flowers and a musical instrument to the writing on a piece of paper: vanitas vanitum et omnia vanitas. As if Bailly wished to go over the dialectical polysemy by getting hold of as many symbols as possible in just one work.

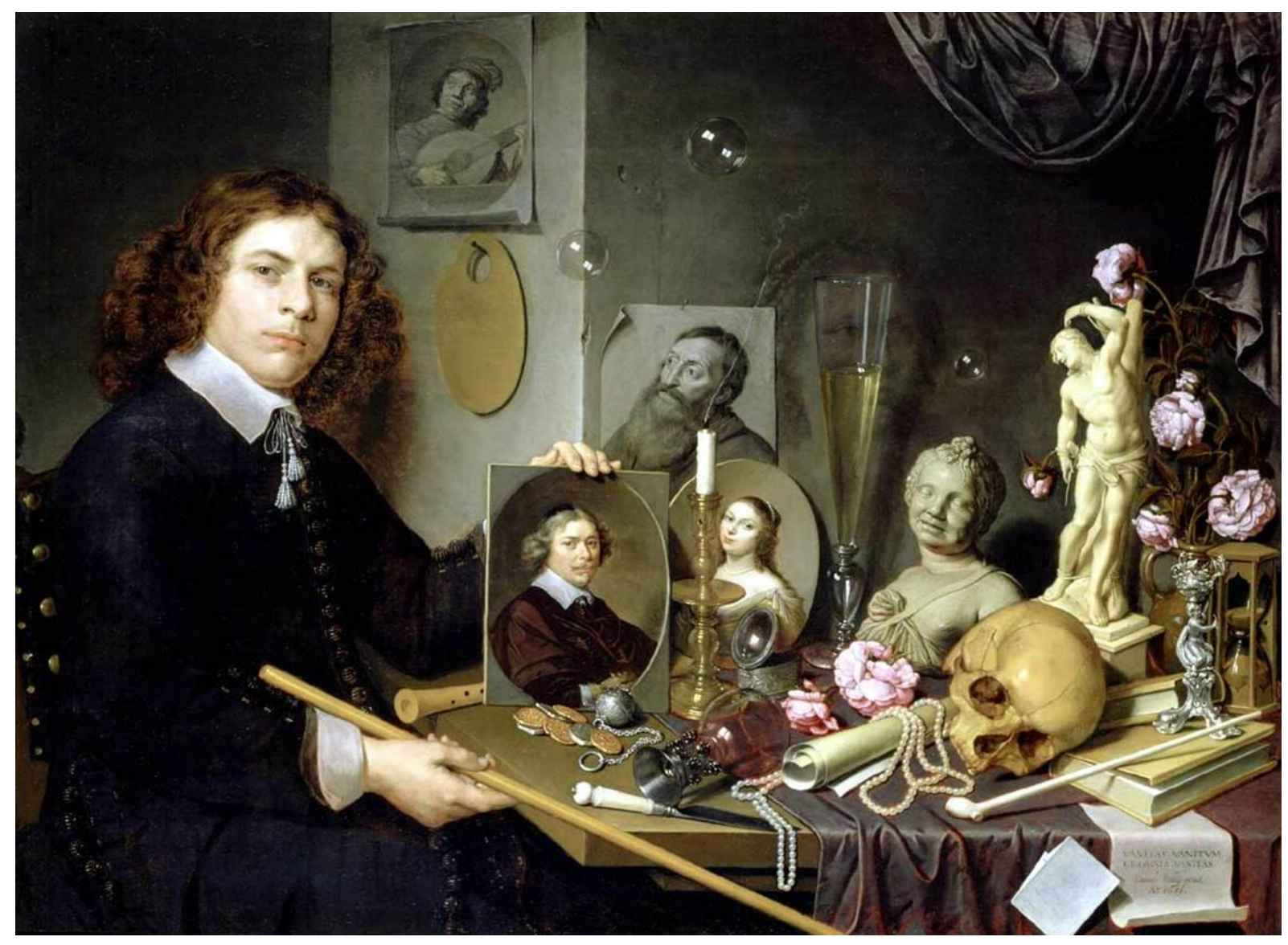

David Bailly - Vanitas (1651) 65 × 97.5 cm (Wikipedia)

In comparison, Fabritius' View is light and open. The symbols are present: the music instruments, the church, the washed out swan on the street sign, the gaze of the man, the washer woman looking at the church across the canal, the weathered wall with the painter's name on it and, although it is almost a quarter in size compared to Bailly's, and the symbols are by far less numerous, its invitation to meditation is perhaps more profound and longer lasting. In a sense, Bailly's Vanitas would be a wonderful exemplification of Fromentin's position on Dutch painting, whereas Fabritius' View would side with Claudel's. One of them going for the snapshot and for democratically giving each symbol its due, the other opting for a less obvious representation, using only pointers and 
manipulating the way we look at it. Transience, as we saw, is also part of the viewing process. Through the perspective box, the sight we are presented with is also transitory. One could only see it as long as one peeps through the hole. You cannot look at this picture in passing, have it hanging on a wall and, while going from a room into another, have another quick glance at it. You have to actively look at it in order to see it. As it is/was the case with music - you have to actively play it in order to hear it. Some think that the music instruments seller is actually a self-portrait, a Fabritius who somehow lost part of the exuberance and visceral features present in the self-portrait from 1645, for example. If true, the person painted not only deals with objects that make time palpable but is, simutaneously, the painter himself who makes space not only palpable but, as is the case with the View in Delft, also ephemeral.

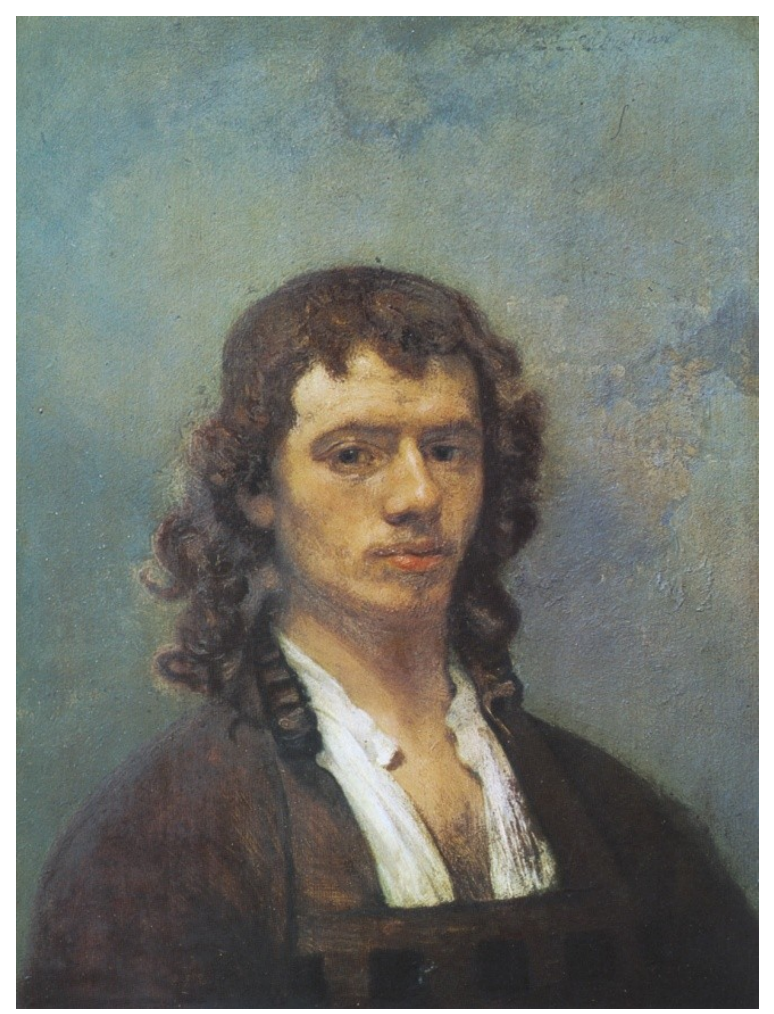

Carel Fabritius - Self Portrait (1645) 65 x 49 cm (Wikipedia)

Fabritius is challenging the viewer and the idea we have of vision itself (at least for a viewer of his time). In a way, he offered us a chance to see "how we see". View in Delft, even if it is just a "screen", a piece of canvas mounted on a wall inside a box, is reminiscent of the screen that is the eye itself (the retina, to be more precise). The painter fixed the view on the canvas as the observer or the spectator fixes the view on the back of his eye. As Barthes once put it, "Depth is born only at the moment the spectacle itself slowly turns its shadow toward man and begins to look at him." (Barthes, 12) And this is true not only about the depth as perspective in the painting but also about the depth as tradition from which Fabritius comes and which he manages to surpass. By inviting us to reconsider the way we look at the world, by questioning the reliability of vision and by 
pointing out doubt and transience where we hoped to find certainty and eternity, Fabritius' View in Delft does become a metaphor not only for mediation but also for meditation.

\section{References}

Barthes, Roland - Critical Essays. Northwestern University Press. Evanston, Illinois, 1972

Brusati, Celeste - Viewing Dutch Pictures in Real Time. Art History. November, 2012

Damisch, Hubert - The Origin of Perspective, MIT Press 1995

Deleuze, Gilles - Plato and the Simulacrum: October, no. 27 (winter 1983)

Deleuze, Gilles and Guattari Felix - What is Philosophy: Verso, London, 1994

Descartes, René - The Philosophical Writings of Descartes. Cambridge University Press. Cambridge, 1985

Fromentin, Eugene - Les maitres d'autrefois : Belgique-Hollande. Plon. Paris, 1877

Gal, Ofer and Chen-Morris, Raz - Baroque Optics and the Disappearance of the Observer: From Kepler's Optics to Descartes' Doubt. Journal of the History of Ideas, Volume 71, Number 2, 2010

Grootenboer, Hanneke - The Rhetoric of Perspective, University of Chicago Press, 2006

Holmes, Charles - Carel Fabritius: The New Portrait. The Burlington Magazine for Connoisseurs, Vol. 46, No. 264, 1925

Jameson, Frederic - Postmodernism, Or, The Cultural Logic of Late Capitalism, Duke University Press, 1991

Kelly, Anthony - Paul Claudel on the poetry of seventeenth-century Dutch painting. Word and Image, Vol.19, NO. 3, 2003

Liedtke, Walter A. - The 'View in Delft' by Carel Fabritius. The Burlington Magazine for Connoisseurs, Vol. 118, No. 875, 1976

Massumi, Brian - Realer than Real: The Simulacrum According to Deleuze and Guattari. Copyright no.1, 1987

Merleau-Ponty, Maurice - The Visible and the Invisible, Evanston: Northwestern University Press. Evanston, Illinois, 1968

Most, Glenn W. - Mimesis in Craig, Edward - Routledge Encyclopedia of Philosophy, Taylor and Francis, 1998

Olds, Clifton - Wollheim's Theory of Artist as Spectator: A Complication. Journal of Aesthetic Education, Vol. 24, No. 2, 1990

Valentiner, W. R. - Carel and Barent Fabritius. The Art Bulletin, Vol. 14, No. 3, 1932 
Wollheim, Richard - Art, Interpretation, and the Creative Process. New Literary History, Vol. 15, No. 2, 1984 